\title{
Making sense of the combined degree experience: The example of criminology double degrees
}

\author{
Kerry Wimshurst \& Matthew Manning \\ School of Criminology \& Criminal Justice \\ Griffith University
}

\begin{abstract}
Little research has been undertaken on student experiences of combined degrees. The few studies report that a considerable number of students experienced difficulty with the contrasting epistemic/disciplinary demands of the component programs. A mixed methods approach was employed to explore the experiences of graduates from four double degrees that combine criminology with a second degree. While participants experienced epistemological uncertainties, most worked out ways, individually and in groups, to accommodate the tensions associated with combined degree study and to make sense of their experiences. A common means of coping was to enlist the disciplinary perspectives of one field as a lens to make sense of the other. At the same time, participants reported that there was little in the way of curriculum and pedagogical provisions to help them to establish connections between their degrees. As one participant stated, 'it was all [done] on our own'.
\end{abstract}

\section{Introduction}

Double degrees are known by various names, including combined and dual degrees, and typically refer to a program of study that combines two degrees in different but related fields. These degrees are usually taught conjointly over a shorter period than would normally be the case for the two separate degrees. Research on student experiences of combined degrees is surprisingly sparse, given that there have been offerings of degree combinations for more than thirty years (see, Malone 1985). Provision of combined degrees in Australia has increased in the last ten to fifteen years (Hickey, Sumsion and Harrison 2010). While only about 10\% of Australian bachelor level graduates have undertaken combined/double degrees, there is considerable variation by region and particularly by field of education, with the highest concentrations in law and legal studies (26.5\%) and business and engineering both averaging about 15\% of bachelor graduates (Graduate Careers Australia 2012, 
2013). The school of criminology and criminal justice featured in the present study has approximately half of its undergraduates enrolled in combined programs. Double degrees tend to get favourable media coverage (eg, Hare 2012; Lewington 2013), and there has been considerable growth in international offerings, particularly based in the USA, aiming to compete in global higher education markets (Knight 2009; Obst, Kuder and Banks 2011).

The limited research and evaluation literature on combined degrees focuses on program rationales and structures and related administrative problems, but rarely deals with student experiences of studying in such programs (Michael and Balraj 2003). When students are considered, emphasis is placed on the career 'head start' that double degree graduates supposedly gain over their single degree competitors (Obst, Kuder and Banks 2011). There is some evidence that combined degree graduates are more successful in accessing full-time employment than single degree graduates (Graduate Careers Australia 2012, 2013), but there is a dearth of exploratory and explanatory research on how combined degree students experience their programs.

Yet, such experiential research is important since even a passing knowledge of the limited literature, and some familiarity with combined degree students, reveals tensions and mixed views about their experiences. Students who come into double degrees often have high tertiary entrance scores, indeed Geifes (2009: 29-30) refers to them as among the 'best and the brightest'. They tend to have determined ideas about career directions, and they usually enter their program of first preference. On the other hand, the few studies of their experiences, as noted shortly, indicate ambivalence, even negativity, when students reflect upon the combined degree experience. The aim of the present study was to explore how graduates had come to understand, or made sense of, their experiences in double degrees. The case is based on a suite of criminology and criminal justice double degrees.

\section{Making sense in combined degrees}

The concept of sensemaking draws upon Weick's (1995) model which contends that people enmeshed in organisations (including formal learning environments) are always in the process of interpreting situations as they attempt to bring a sense of 
order to complex learning experiences. Making sense of one's experiences is fundamental to the maintenance of self-identity. It is an ongoing process that necessitates drawing upon previous experiences and knowledge while attempting to reconcile these with current (perhaps confusing) experiences. It is also a process that is inextricably related to one's expectations for the future.

As this study progressed participants mentioned often a coping strategy reminiscent of Weick's (1995) notion of 'extracting cues' from problematic situations. Cues are like markers or signposts that assist one to firstly identify puzzling discrepancies or learning conundrums, and then assist the learner to think through uncertainties and tensions and hopefully to achieve some reconciliation. Participants in this study were alerted to conundrums and then attempted to reconcile their doubts by way of making comparisons between their component degrees, comparing different school environments, and comparing themselves with fellow students in single degrees. Sensemaking is concerned with students establishing a sense of 'order, clarity, and rationality' (Weick 1995: 29) but not necessarily about arriving at objective ‘truth’ or 'accuracy' as these may be defined by other stakeholders, such as academic staff and program developers. As Weick (1995: 56-57) notes: 'Sensemaking is about plausibility, pragmatics, coherence, reasonableness, creation, instrumentality (and that which is also interesting, attractive, emotionally appealing, and goal relevant)'. That is, if their own definition of a situation makes sense to learners, they are on their way to coping with tensions and ambiguities.

\section{Research on students in combined programs.}

In fact, the few empirical studies of student experiences of combined degrees have arrived at similar conclusions, finding that students expressed dissatisfaction with perceived disjunctures in their programs. Russell, Dolnicar and Ayoub (2008) noted that 'programs of study combining two bachelor degrees [were] becoming increasingly popular in Australian universities'. They reported, however, 'considerable dissatisfaction' among double degree students who were attempting to cope with contrasting learning styles, standards and expectations between academic elements. Some students 'responded by dedicating less time to one of their degrees, and many described difficulties in reaching their potential academically’ (2008: 584). The conclusion was that many double degree students felt excluded from a 'learning 
community' to the detriment of their performance and persistence. The blame for this situation fell upon 'rigid disciplinarity'. Program providers, it was said, did not endeavour to develop interdisciplinary attitudes and skills.

Similarly, Weissmann (2013) found that students completing joint honours degrees in two different disciplines complained of their ‘sense of isolation' and about feeling 'excluded from the institutional norm' or habitus (the ingrained sense of belonging in a particular socio-cultural environment). Many students claimed they did not feel at home in their combined program. Again, this was attributed to the power of disciplinarity as the traditional hallmark of honours programs. While Weissmann (2013: 261) noted that 'a sense of cohesion [often] had to be created by the students themselves', there was relatively little said in these studies about how students attempted to integrate their learning across not just different disciplines, but across different academic fields.

Other commentators have noted that combined programs may lack a primary convenor whose job is to assist students accommodate the multi/interdisciplinary demands of their programs, effectively leaving students to their own ways of making sense of their experiences (eg, Morgan 2013: 146-148). In the present study, all the combined programs had designated convenors whose role was mainly program and student administration, but they were not expected to provide structured guidance to students in terms of epistemological/disciplinary integration of components. Thomas (2012) emphasises that building a sense of 'belongingness' or feeling comfortable with one's program is fundamental to student engagement. From this perspective, the sensemaking endeavours recounted by participants in the present study can also be interpreted as their attempts to feel more settled ('at home') in their combined degrees.

\section{Context of the research}

The case explored in this study is a set of double degrees in criminology and criminal justice (CCJ). The school offering these programs is situated in a large Australian teaching/research university. In 2014 the school had an enrolment of about 1280 undergraduates in its criminology degrees. Approximately 50\% of these undergraduates are enrolled in a single criminology degree, while the remainder of the 
school's students are enrolled in one of the four combined degrees offered in partnership with other academic elements. The criminology-related degrees featured in the study are:

- The single Bachelor of Criminology and Criminal Justice comprising three years of full-time study or part-time equivalent.

Four combined degrees:

- The Bachelor of Human Services/Bachelor of Criminology and Criminal Justice (CCJ/HuServ) comprising four years of full-time study or equivalent,

- The Bachelor of Psychological Science/Bachelor of Criminology and Criminal Justice (CCJ/PsychSc) comprising four years of full-time study or equivalent,

- The Bachelor of Forensic Science/Bachelor of Criminology and Criminal Justice (CCJ/ForSc) comprising four years of full-time study or equivalent, and

- The Bachelor of Laws/Bachelor of Criminology and Criminal Justice (CCJ/Law) comprising five years full-time study or equivalent.

Criminology and criminal justice remains a rather unsettled field epistemologically, and no doubt this also contributes some uncertainty to student sensemaking. In addition to the disciplinary complexities (the epistemes) of different degree combinations, particular degree fields may remain in flux. For example, the field of criminology and criminal justice displays considerable diversity in Australia, to the point where many programs contain relatively little common core content. The discipline has yet to identify the knowledge and skills, the big threshold or integrative conceptual and experiential encounters, that graduates might be expected to negotiate successfully (Bartels, McGovern and Richards 2015; Wimshurst 2011). It may be that while some traditional fields featured in this study (perhaps law, or psychology) have reasonably settled parameters, the degrees in other combined programs have more unsettled and porous boundaries, in which both components are still in the process of establishing their knowledge base and professional credentials.

It may be better to treat the research discussed here as an 'intrinsic' case study, which Stake (2003) defined as the investigation of a particular instance of a phenomenon, where the particularities of the case remain the focus of the research, but where 
readers may find the case applicable to their own situations. We can only speculate on the extent to which our findings reflect student experiences in other institutions, but certainly the participants, in keeping with the few experiential studies conducted elsewhere, found difficulty in pulling together the disciplinary halves of their double degrees. Thus, on face value, the findings reported here have generalisability to other cases of combined programs. The contribution of the present study is in analysing the the ways participants tried to make sense of this seemingly confusing situation.

\section{Method}

The study adopted a ‘quasi-mixed methods design' (Creswell 2013; Teddlie and Tashakkori 2013). Quantitative and qualitative data were analysed, however the research strategy was not planned as a mixed-methods 'convergent design' where one approach (typically quantitative) is employed to identify questions, which are then addressed in greater depth by way of qualitative methods. Rather, in this study the two parts, quantitative and qualitative, were designed to provide different but related insights into the characteristics of double degree candidates and their experiences. The study was approved by the university's human research ethics committee (CCJ/31/13/HREC).

The quantitative section was based on data held on the university's management systems website which were readily accessible by the researchers. The data set for the analysis consisted of all undergraduates $(n=1125)$ who commenced or continued in criminology-related degrees in semester 1, 2012. The dependent variable for statistical analysis of the cohort was candidacy in any of the five undergraduate CCJ-related programs. Eleven independent variables were explored: study load, gender, age, home language (English/other), country of birth (Australia/other), grade-point-average (GPA), tertiary entrance score, program preference, admission pathway, socioeconomic background, and Indigenous identity. The aim was to establish a quantitatively-informed portrait of similarities and differences between candidates for the one single and four combined criminology degrees. This seemed an important undertaking since little is known about the demographics of students in any of these criminology programs, especially the combined degree candidates who tend to be seen en masse by academic staff as simply 'the double degree students'. 
The second part of the study turned to interviews to explore the dynamics of coping, or the ways that graduates say they made sense of their experiences in double degrees. As the purpose of the study was sensemaking in combined programs, only graduates from the four double degrees were interviewed. Initially, graduates known to the researchers were approached and then snowball recruitment followed as the original group invited others to participate. Most of the 14 participants, except for those in the $\mathrm{CCJ} / \mathrm{HuServ}$ combination, were postgraduate students, tutors and research assistants in the school of criminology. The human services/criminology graduates had moved into the workforce or were looking for employment. The participants were interviewed separately, once only. In terms of ethical considerations, while some of the participants were previously known to the researchers, none of them were being supervised by the researchers for higher degrees, nor were they employed as tutors or research assistants by the researchers. Many of the participants would have been familiar to each other, at least by sight, but an effort was made to ensure that comments reported in the study could not be easily attributed to individuals, by staff or other graduates. The fact that the group was self-selecting may have introduced an element of bias, but while some sensemaking strategies seemed characteristic of particular programs (as noted later), similar points were often raised by graduates from different programs, by informants who apparently did not know each other. Interview sessions lasted between 15-45 minutes, with an average of just under 30 minutes. The participant with the shortest interview was unwell on the day. In total, about six and a half hours of recorded interviews were conducted and transcribed.

Interviews were based on a semi-structured schedule. Participants were provided with the five main questions about two weeks before the interview. They were encouraged to treat the questions as prompts only, to address them in any way they saw fit and were invited to talk about any other issues related to their combined degree. The core questions are listed below. The information sheet stressed our intention to explore how the participants made sense of the experience of doing a double degree. Themes relating to sensemaking and of coming to understand the connections between degrees and disciplinary fields were then extracted from transcripts for further consideration. Quotations were drawn from the transcripts, and have been 'cleaned', following Woods’s (2006) advice, by removing repetitive ums and ahs, and by occasionally 
editing passages in order to clarify the participants' comments. Participants' names have been changed.

\section{Core interview questions}

1. Thinking back, why did you do your double degree?

2. How has doing your double degree contributed to your understanding of either one or both of your academic/professional fields?

3. More broadly, how do you think doing the double degree has contributed to understanding your own life?

4. If you had to nominate a concept or idea or experience that pulled your degree(s) together, or helped you to make sense of your program of study, what might that insight have been?

5. Is there anything else you would like to tell us about your experiences of doing the double degree? Any last thoughts?

\section{Student demographics}

As shown in Table 1, there was a significant relationship between each of the independent variables and candidacy in the programs, except for Indigenous identity. Only 26 (2.4\%) of students identified as Indigenous which did not permit statistical analysis across five programs.

The analyses for Table 1 indicate significant differences across programs. The effect size is the measure of the strength of demographic differences between two or more of the programs. Thus, tertiary entrance score, for example, has a large effect in differentiating the programs. To this end, Table 2 based on the same data set highlights the highest and lowest proportions of students for each of the independent variables. That is, while Table 1 indicates that there were significant statistical differences across programs, Table 2 shows the numerical or proportional differences between programs. The purpose of this study was not to compare degree combinations, and such a fine-grained comparison between double degrees was not attempted in the interviews with graduates. However, it is clear that students in the CCJ combined degrees cannot be seen en masse simply as 'the double degree students', there are considerable demographic differences. It also seems likely that students bring different personal resources and characteristics to their combined 
degrees, which have implications for the ways they make sense of their programs, as noted in the following comparison.

\section{Double degree demographic differences}

A comparison between the two smaller programs illustrates these differences. Each of these programs had a very high proportion of female students enrolled (over 85\%), but thereafter Table 2 indicates considerable differences on many of the other demographic variables. The two programs are here summarised and potential implications for coping/sensemaking touched on, implications that are developed later in the qualitative analysis.

CCJ/HuServ: The human services/criminology double degree had the highest proportion of students carrying less than a standard full-time study load. It had a higher than average proportion of older students, although the majority were still young. Some students already worked in community services and so carry a lighter study load. On the other hand, a number of students have entered the program with lower than average entry scores and their GPAs remain lower than average for double degree students, both of which may contribute to students cutting back their study load. The number of students who received their first preference program upon entry was also lower than average, although a solid proportion (68.9\%) had still achieved their program preference. The program had the highest proportion from lower socioeconomic localities, although there was something of a bifurcation here since the program also had a relatively high proportion from higher socio-economic backgrounds. The profile suggests a very mixed group of candidates in this double degree. Yet, it is also likely that students with work experience who are older can provide fellow students with mentoring and insights into the welfare/human services industry. Indeed, the interviews later indicated that this double degree encouraged a congenial social environment in which graduates reported group or peer efforts to make sense of their combined programs.

CCJ/ForSc: The forensic science/criminology program indicated almost the reverse portrait in terms of demographic characteristics. A very high proportion of students carried a higher study load, with additional subjects and time spent in laboratories. The students were overwhelmingly younger than the average across programs. Students entered directly from secondary school. This combined degree had the 
highest proportion with good entry scores, and the highest proportion with good grade-point-averages. It had the highest proportion (88.4\%) who had been offered a place in their first preference program. The group had the highest proportion of students from middle class backgrounds. The profile suggests a group of high performing candidates in this double program. Their high achieving status may help to explain why graduates interviewed later reported that they became disgruntled by the apparent lack of employment in the field, and increasingly made sense of their predicament by contrasting and distancing themselves from students who were completing a single forensic science degree.

\section{TABLE 1 ABOUT HERE}

\section{TABLE 2 ABOUT HERE}

\section{Career aspirations, motivation and tension}

While students in single degrees are no doubt concerned about employment, the double degree interviewees kept returning to the theme of employment and careers. Combined degree entrants have quite specific ambitions, which of course may change during their studies, but they have thought carefully about the degree combinations that might fulfil these initial ambitions. If and when uncertainties emerge about the ways their combined programs fit together, tensions are keenly felt in terms of doubts about one's academic identity and competence, at least until some reconciliation of epistemic tensions can be brought to bear. Combined degree entrants have often invested heavily in achieving good tertiary entrance scores to get into their preferred programs. Thus, while there were considerable demographic differences between the combined degrees, Table 2 indicates that an average $72.1 \%$ of double degree students had higher entry scores compared with $37.6 \%$ of single criminology degree students, and $75.0 \%$ of double degree candidates received their first preference program on entry, compared with $60 \%$ of single degree students.

Interviews with the graduates indicated that concerns about future prospects in their preferred disciplinary/professional field remained uppermost throughout their programs. For example, Jack, one of the graduate interviewees, recalled that he originally commenced the single psychology program but, concerned about limited employment prospects, transferred into the combined degree in second year to 'hedge 
[his] bets'. While some participants also believed that a double degree would provide a 'more rounded education', the driving concern for choosing a combined program was their hope that its possession would be 'more attractive in terms of job prospects'.

Angelica confirmed the centrality of concerns about employability and provided insight into the ways candidates selected a combined degree with a view to their futures. She reflected on the way that double degree students usually referred to their programs as 'psych and crim' or 'law and crim'. Typically, entrants to combined programs initially settled on a degree related to their intended vocations, such as the law, psychological counselling, youth welfare, or crime scene investigation, and then looked for a complementary second degree, which in the present case was criminology. She added that many of them 'worried' about gaining employment or scholarships in what they saw as their 'main' area. Like herself, many came to value criminology, they were now postgraduates and tutors in the area, but in the hothouse of competition for jobs, scholarships, and entry to higher degrees in what initially had been their preferred field, the criminology program often remained a secondary consideration until late in the day.

\section{Making sense of two fields}

\section{$\underline{\text { Sense of separation between components }}$}

Ten of the fourteen graduates reported that they felt little sense of fit between their degrees. Olivia said that she and her friends (CCJ/ForSc) had to make sense of the fit between fields themselves. She added that ways could always be found, but that these were 'not overt'. By this she meant the links had not been established clearly from the start by way of the curriculum or pedagogy. In fact, none of the double degrees contain a foundation subject designed to establish a sense of integration between components. Two of the psychology graduates felt the degrees 'married together really well', although they perceived this fit somewhat narrowly in terms of complementary academic skills such as gaining a good understanding of research methods and statistics, rather than achieving a sense of epistemological balance between contrasting fields of knowledge and/or views of the world.

Two of the CCJ/HuServ graduates also reported a sense of fit, but the realisation came late for both. For example, Lucy felt that 'content wise, [there was] a good fit', but 
she added that it 'didn't seem the two schools communicated or talked'. She described the way her sense of fit came with her first full-time job, some eight months after graduation. She found herself working with police and teachers in youth welfare, and saw herself as something of a workplace intermediary between criminal justice, youth work, and other professionals. She noted that her employment finally pulled the two degrees together in her mind. A second CCJ/HuServ participant reported similar insights during a youth justice practicum in the fourth year of his program.

Also in my placement, when I was actually in the field and working with youth justice, we had the theory of criminology and we had to use basic interventions for these people. We also bring in theories of social welfare and ideas of social development from human services. Then I could see it in practice. I could say ah! so what they taught us in class, that's how you could implement it here. That was a real key moment in just understanding the course and the relevance of all of the things that we'd been taught.

However, for the other interviewees, their double degrees did not coalesce in their thinking into a coherent whole. Nadia, despite individual mulling over of things and talking with other students, always felt a sense of separation between the degrees (CCJ/PsychSc): 'I never felt they completely meshed together. As you're studying and you're reading you can see different connections and things like that, but they still felt separate'. Angelica recounted the way her degrees seemed to occupy different spheres. She felt that ultimately she would have to choose one or the other disciplinary field in order to pursue a career or even to enter postgraduate studies. She concluded her interview with the observation:

I think the only other thing I can add is I had always considered throughout my undergrad, and I don't know why I had this in my mindset, that psychology was one degree and criminology was a different degree so I never sort of really interrelated them much. [...] I'd always sort of considered that I had to choose one pathway or the other and I don't know why that stuck in my head because, in hindsight, it's such a silly concept to think about.

Thus, perceptions of fit between the two fields did not come early to most of the participants. More often, any sense of integration came late, sometimes only after 
graduation. Whether coming early or late, the strong impression left by the interviews was that participants had to arrive at their own understandings of complementarity.

\section{Individual and group understandings}

Making sense by way of individual reflection and/or cooperative effort were not mutually exclusive coping strategies, but among the interviewees there were indications of a disciplinary demarcation between individual and group ways of making sense of one's double degree.

Law and psychology graduates were more individualistic in grappling with sensemaking. For example, Simone noted of her CCJ/Law program that she had to think through how the degrees could fit together. There was, she says, always some aspect that 'helped complement each', but nothing explicit in either degree was taught that integrated the two areas. In fact, like other individualistically inclined sensemakers, her strategy was to enlist one area (law) to inform an understanding of the other (CCJ). In this way, for her the two areas came together 'in the end', but largely through her own reflections. Indeed, for the entirety of the combined program, she felt the two degrees were 'quite separate', more so in later years as specialist courses were introduced into both.

On the other hand, the $\mathrm{CCJ} / \mathrm{HuServ}$ graduates reported they had made sense of their program by forming a supportive group who worked together through the program, helping each other develop meanings from their experiences. Kirsten notes that 'we really helped each other through it all'. Lucy provided an illustration. After 'gravitating towards each other', the group of five or six found that they could help each other by applying 'concepts from each field back and forth, so we would talk about how we would do that'. She suggested that the demands of coping with a combined degree virtually precluded developing working relationships with students from the single degrees:

I would try to put in my human services assignments, where possible, criminology concepts and vice versa, whereas if you would hangout with students from just one or the other [degree], they don't have that common [understanding], they'd be like, what?' 
Dylan added that because they were able to take some alternative subjects from either degree, they would compare different ideas they encountered in their solo studies, thus helping each other achieve a better sense of connection between fields. Susan said that even when members of the group began to take courses by external studies, they would still arrange meetings by email: 'by then we had our established group of friends, so we would have a study day together and figure it out together'.

These findings confirm the importance of informal student 'learning communities' in making sense of their programs (see, Havnes 2008; Orsmond, Merry and Callaghan 2013). Obviously students have always helped each other informally to cope with their studies, but the $\mathrm{CCJ} / \mathrm{HuServ}$ graduates in the present case constituted a semiformal grouping, one with a pronounced sense of bonding, and one that was more than a few friends helping each other as the need arose. They were a group that had been self-generated, quite apart from any groups established by academic staff for pedagogical purposes, and their organisation was certainly not a haphazard arrangement. Rather, they had to work at maintaining their relationship over four years, helping each other make sense of the contrasting disciplinary demands of their combined program. In fact, given Lucy's comment noted earlier about the lack of communication between schools, it seems that this tight group had reason to rely on each other's insights, instead of turning to academic advisors for assistance in sensemaking. It was also the case that these graduates felt that the school of human services 'felt more like a community'. Susan noted that some human services staff had encouraged the double degree students to persevere but that 'they [staff] didn't really understand what criminology was', and so could offer little specific guidance on the problems of combined epistemes.

\section{The what and how of making sense}

While it was clear that these graduates largely had to do their own sensemaking, individually and in groups, the question remains as to how and why the participants came to recognise epistemic tensions in their combined programs. The study draws upon Weick’s (1995) notion of 'cue extraction' as a core characteristic of making sense in confusing learning environments. Somewhat paradoxically, over and again these graduates would first become aware of discrepancies between component programs, but then it was their attempt to reconcile differences that helped to re- 
establish their sense of learner identity, although they did not always arrive at a sense of cohesion between component degrees.

\section{$\underline{\text { Recognising contrasting disciplines and practices }}$}

Participants commonly made sense of one field by viewing it from perspectives borrowed from their second degree. That is, knowledge and processes that characterised one field, usually the field with which the participant felt more comfortable, became the epistemic lens for comprehending the requirements of the second field. For example, Wendi entered her program directly from secondary school and found that criminology came to her 'more easily'. She 'struggled' with psychology at first, but then realised that her understanding of criminological concepts might be used to understand psychological theories. It seems that she had intuited that since psychology was one of the foundational disciplines in criminology, there had to be major links between the fields, if she could discern them. At that point, toward the end of first year, she says she knew she could succeed in psychology if she could 'find a criminological twist to it'.

Examples of conceptual insights that helped to integrate two degrees were not common in the interviews, but there were some, which suggests that the inclusion of structured, curricular linkages between powerful, integrative concepts (see, Meyer and Land 2006) when planning double degrees may assist student sensemaking. For example, Kirsten related the way she was listening to a human services lecture on theories of poverty and suddenly realised that 'a lot of them were like a lot of crime theories'. The relation between poverty and crime is, of course, complex, but Kirsten's connection here between 'big' concepts had considerable impact on her making sense of her double program:

It was like the words were almost interchangeable, and it was okay, I can see exactly how [things fit], because it's known poverty is a factor in criminality. I saw at that point, I could really see the correlation, I can see why I'm doing these two degrees together. Yeah, that was really good.

At first, like her peers in the CCJ/Law double degree, Simone's interest was primarily law, but her academic interests and professional activities increasingly leaned toward criminology, albeit informed by a legal framework. She noted of her double degree 
that 'the law [had] probably contributed to the criminology degree more than the other way around'. Her legal knowledge enabled her to work as a researcher and tutor in both areas, and helped structure her thinking about issues in criminal justice. The participant was obviously talking in epistemic terms. That is, disciplinary knowledge as a way of structuring and processing both academic and professional activities, and one's life more broadly: 'It was one of the things that I like about law and I think it helps with the criminology area as well. There is a process to follow [...] it's about having the best argument and using evidence to your benefit'.

As discussed in the next sub-section, an emergent theme was that participants tended to explain themselves and their experiences by comparing themselves with students in the single degrees. In terms of contrasting epistemes, the CCJ/Law graduates felt that single degree criminology students could not, or would not, comprehend legal perspectives or bother themselves to find out more about legal ways of reasoning which, in the informants' views, added rigour to the study of criminology. Tamsin said that the criminology students did not have sufficient grasp of, or interest in, the centrality of law in the criminal justice system. She said the CCJ students simply thought that legal studies 'just broadens their knowledge a bit'. Simone felt that CCJ students (and staff) tended to separate law out from the main business of criminology and did not appreciate legal ways of analysis and reasoning: 'I find that even from marking [criminology] students' assignments, they kind of go off track, they're not very structured in the way they approach their subjects'. Both participants were clearly saying that taking their conjoint law degree also made them feel that they were stronger criminology students, even when they could discern no formal meeting between programs.

\section{Comparing fellow students and constituent schools}

The participants were well aware of disciplinary differences and inherent epistemological tensions. The awareness, however, as suggested by the previous example, was typically manifest in comments about differences between themselves and single degree students, and/or differences between school environments. These perceptions were the cues extracted from complex learning situations to assist in sensemaking. For instance, the CCJ/ForSc graduates saw clear differences between students in each of the single degrees which constituted their combined program. 
Maddy, it seemed, was one of the few interviewees who always experienced difficulty arriving at any sense of meeting between her two degrees. To her, each program was offered on a different campus and she saw the students in the constituent degrees as very different. She said 'the two degrees did not complement each other much, [but] ran parallel', indicating with her hands in the interview two paths running on parallel tracks. Maddy coped (made sense) by accepting that her two degrees were completely separate, as would remain her experience of both programs. Reflecting on both degrees, she concluded: 'it was just a whole different world really'. She sensed the disciplinary separateness especially in terms of pedagogy and assessment practices. When the researcher asked if she and her friends 'swapped hats between campuses', Maddy replied:

Yeah, I think we just swapped, especially in the first two years. Here [CCJ] it was all thinking this theory says this, things like that. Then you'd have to switch. Over there, it would be rote learning of these facts to apply in situations. Yeah, I think we enjoyed the criminology stuff because we found it easier than the science stuff sometimes. We'd be like okay, got to write a [crim] essay. That's easy [laughs].

Her fellow, Olivia, spoke of the science environment as 'like being in a forensic science bubble'. She had earlier commented that criminological insights provided meaning to the 'why' of forensic science, but added that there was relatively little contribution to understanding the rationale for the double degree flowing from the science side. Clearly, both young women had been very good at science in secondary school, they had to be to get into their combined program, and both initially wanted to work in crime scene analysis, but they were increasingly finding their science studies restrictive. Both were leaning more to interests in crime prevention and youth justice. It seemed that contrasting disciplinary ways of viewing and operating on the world were allowing less room for accommodation with each other. These epistemic tensions were exacerbated for both of them by what they saw as a lack of career opportunities in forensic science.

Lucy recounted her experiences in both her schools. She was really commenting, of course, on her encounters with contrasting disciplinary fields, different kinds of professional socialisation, and her responses to the different pedagogies that 
characterised her academic and professional domains. She became keenly aware of contrasting school environments.

A big part of the human services degree is talking a lot, which you do with clients, is talking about how you feel and how they feel. So there's lots of expressing feelings, whereas when you come over to criminology, you tend not to do that so much in tutorials. In our tutorials for human services, we would talk about whatever the assessment was. We'd also talk about how we feel about the assessment and how is the assessment affecting your life. Are people struggling with that? I'm like, what? Which is weird, because I then went into counselling. I'm not a really big over-sharer. Lots of people at human services are very over-sharing, so they would share lots of personal things in tutorial classes, and [I'm thinking] is this really relevant?

Simone also commented on contrasting professional and discipline-related characteristics of the respective school environments. In particular, she noted the paradoxical relationship between competition and collegiality that characterised induction into the legal field. She began by noting that 'when you go into law school, there is definitely a particular personality type, quite competitive, can sometimes be a bit bitchy and argumentative, and usually quite organised'. Yet, within this highly competitive environment, professional socialisation must, of necessity, instil in neophytes a sense of strategic, corporate endeavour.

One difference I would see between the two schools is that within the students at the law school they work more together. They socialise more together and you get to know a lot of people, just other students. Because the legal profession is such that when you go along, you will meet other people that you did your degree with and you rely on those relationships. Law encourages that kind of collegiate attitude, working with each other. I think the school of criminology, I find it very segregated, that students don't socialise. But by the same token, within the school of criminology, I think that the lecturers and the people that you interact with, your tutors, are more approachable. So you have a different element to it.

In summary, the double degree graduates contrasted their own epistemic/world views and experiences, which they saw as more expansive or flexible, with the perceived 
narrowness of students in the single degrees. It was not necessarily a case of dismissing the single degree students as less capable, rather there was the perception of having less in common with them as they all moved further into their respective single and double programs. There was also the belief that single degree students could not understand the expectations and demands placed on combined degree students, or the strategies the latter developed in order to cope with contrasting epistemes.

\section{Conclusions}

As noted earlier, Lucy made the comment that it 'didn't seem that the two schools communicated or talked'. According to graduate interviewees, participants may have encountered disjunctions most immediately in the day-to-day administration of programs, such as timetabling clashes, turnover of responsible staff, and lack of understanding among individual degree convenors of the other half of the combined program. However, in terms of the bigger picture, different epistemological traditions, differing student clientele, and different school environments also contributed to the sense of separation between components. Paradoxically, yet fortunately for these graduates, once participants had worked out for themselves, by noticing and thinking about relevant cues (Weick 1995), that what they were experiencing were inherent disciplinary and school differences and not the result of their own misunderstanding or lack of application, then they were able to move on to making at least partial sense of these differences.

Russell et al (2008) found that students experienced considerable frustration making sense of the competing demands of their constituent programs to the extent that 'some students responded by dedicating less time to one of their degrees' (2008: 584). In the present study, a common strategy was to use the disciplinary insights and perspectives from one degree to complement or unpack the other, rather than one downgrading the other. This was a coping strategy that the participants had arrived at themselves. They certainly had not been inducted into ways to approach multidisciplinary studies. Admittedly, the graduates interviewed in the present study have been successful. To a person they came through their programs with better-than-average grades, and many have moved into higher degrees. It may be that other candidates, perhaps those who were not part of supportive peer working groups, or who as individuals were less 
adept at reconciling coexisting epistemes, had to resort to the kinds of coping reported by Russell et al (2008).

Indeed, perhaps the 'less successful' did not cope with the paths they set themselves. There is evidence of movement back and forth between enrolments in combined and single degrees. Student academic transcripts sometimes indicate a number of such moves during their undergraduate careers. Single degree students transfer into combined programs looking to, as they believe, improve their employment chances, which was the reason provided by our participants for deciding on entry to a double degree in the first place. Others in combined programs find the going gets increasingly harder and transfer back to single programs. There is also some movement between double degrees. The study did not attempt to incorporate research on movements between programs, but future research might gather stories about such volatility. Student reflections may say important things about the value they place on both single and combined degrees, and the reasons they have for moving around between programs. Further research might also investigate the strategies employed by the less-than-succcessful students as they try to make sense of their experiences in double degrees.

Future research might explore the efficacy of introducing (structured) integrative activities into combined degrees. While Michael and Balraj (2003) did not explore student experiences, they were correct to insist on the need for rigorous monitoring and evaluation of combined programs. In particular, such monitoring needs to explore ways students may be assisted to make epistemic and professional connections between component programs. For example, only one of the combined degrees featured in this study has a capstone subject in the fourth and final year intended, among other objectives, to consolidate a sense of integration between the parts. The research reported here indicated that students (and graduates) did not see the connections as readily as academic staff who designed and implemented the double degrees.

Thus, as noted when Kirsten made the link between theories of poverty and crime, one conclusion may be that (planned) examples of conceptual connectedness could be explored with students from early in their double programs. However, this conclusion 
is by no means certain, since the timing of integrative activities/interventions remains problematic. Too early, students have little experience on which to base their understandings, while capstone courses in their final year are rather late to attempt to induct them into strategies for exploring combined disciplinary and professional fields. By then, some will have made sense of connections in their own ways, as demonstrated in this paper, while others may never make meaningful connections.

\section{References}

Bartels, L., A. McGovern, and K. Richards. 2015. Degrees of difference? A preliminary study of criminology degrees at Australian universities. Australian and New Zealand Journal of Criminology 48, no. 1: 3-23.

Creswell, J. 2013. Controversies in mixed methods research. In Strategies of Qualitative Inquiry, $4^{\text {th }}$ edition, ed. N. Denzin, and Y. Lincoln, 101-134. Los Angeles: Sage.

Geifes, S. 2009. Joint and double degree programs: Changing motivations. In Joint and Double Degree Programs: An Emerging Model for Transatlantic Exchange, ed. D. Obst and M. Kuder, 29-30. New York: Institute of International Education.

Graduate Careers Australia. 2012, 2013. Graduate Destinations: A report on the work and study outcomes of recent higher education graduates for 2011 and 2012. Retrieved February 23, 2014, from http://www.graduatecareers.com.au/research/research reports/graduatedestinations/

Hare, J. 2012. Double degree a vertical head start on a masters. The Australian, 8 August.

Havnes, A. 2008. Peer-mediated learning beyond the curriculum. Studies in Higher Education 33, no. 2: 193-204. 
Hickey, N., J. Sumsion, and L. Harrison. 2010. Nursing double degrees: A higher education initiative in times of nursing shortages. Australian Journal of Advanced Nursing 28, no. 1: 52-59.

Knight, J. 2009. Double and joint-degree programs: Double benefits or double counting. International Higher Education, issue no. 55, Spring: 12-13.

Lewington, J. 2013. One student, two countries, two degrees; Dual degrees [...] give participants a chance to stand out in the crowd. The Globe and Mail, 13 March.

Malone, J. 1985. Double degree courses: A viable proposition for the CAE sector. Higher Education Research and Development 4, no. 2: 145-157.

Meyer, J., and R. Land. 2006. Threshold concepts and troublesome knowledge: An introduction. In Overcoming barriers to student understanding: Threshold concepts and troublesome knowledge, ed. J. Meyer, and R. Land, 3-18. London: Routledge.

Michael, S., and L. Balraj. 2003. Higher education institutional collaborations: An analysis of models of joint degree programs. Journal of Higher Education Policy and Management 25, no. 2: 131-145.

Morgan, M. 2013. Reorientation and reinduction to study. In Supporting Student Diversity in Higher Education: A practical guide, ed. M. Morgan, 139-155, London: Routledge.

Obst, D., M. Kuder, and C. Banks. 2011. Joint and Double Degree Programs in the Global Context: Report on an International Survey. Institute of International Education, www.iie.org.Research-and-Publications/Publications-and-Reports/IIEBookstore/Joint-Degree-Survey-Report-2011

Orsmond, P., S. Merry, and A. Callaghan. 2013. Communities of practice and ways of learning: Charting the progress of biology undergraduates. Studies in Higher Education 38, no. 6: 890-906. 
Russell, A., S. Dolnicar, and M. Ayoub. 2008. Double degrees: Double trouble or twice the return? Higher Education 55, no. 5: 575-591.

Stake, R. 2003. Case Studies. In Strategies of Qualitative Inquiry, $2^{\text {nd }}$ edition, ed. N. Denzin, and Y. Lincoln, 134-164. Thousand Oaks, CA: Sage.

Teddlie, C., and A. Tashakkori. 2013. Mixed methods research: Contemporary issues in an emerging field. In Strategies of Qualitative Inquiry, $4^{\text {th }}$ edition, ed. N. Denzin, and Y. Lincoln, 135-167. Thousand Oaks, CA: Sage.

Thomas, L. 2012. Building Student Engagement and Belonging in Higher Education at a Time of Change: Final Report from the What Works? Student Retention \& Success Programme. London: Paul Hamlyn Foundation/Higher Education Funding Council for England.

Weick, K. 1995. Sensemaking in Organisations. Thousand Oaks, CA: Sage.

Weissmann, E. 2013. Excluded from the institutional habitus: The joint student experience. Journal of Further and Higher Education 37, no. 2: 261-279.

Wimshurst, K. 2011. Applying threshold concepts theory to an unsettled field: An exploratory study in criminal justice education. Studies in Higher Education 36, no. 3 : 301-314.

Woods, P. 2006. Successful Writing for Qualitative Researchers, $2^{\text {nd }}$ edition. London: Routledge. 
Table 1 Summary of chi squares and effect sizes ( $\mathrm{n}=1125)$, semester 1, 2012.

\begin{tabular}{lll}
\hline Independent variables & Dependent variable (5 programs) & Effect size \\
\hline Study load & $\left(X^{2}(8)=440.580, p<.001\right) ; \mathrm{V}=.443$ & large \\
Gender & $\left(X^{2}(4)=45.542, p<.001\right) ; \mathrm{V}=.191$ & small \\
Age & $\left(X^{2}(4)=45.542, p<.005\right) ; \mathrm{V}=.170$ & small \\
Language spoken & $\left(X^{2}(4)=17.635, p=.005\right) ; \mathrm{V}=.125$ & small \\
at home & & \\
Australian born & $\left(X^{2}(4)=11.409, p=.022\right) ; \mathrm{V}=.101$ & small \\
Higher GPA & $\left(X^{2}(4)=23.992, p<.001\right) ; \mathrm{V}=.186$ & small \\
Higher tertiary entrance score & $\left(X^{2}(4)=72.844, p<.001\right) ; \mathrm{V}=.378$ & large \\
Program preference & $\left(X^{2}(4)=42.608, p<.001\right) ; \mathrm{V}=.206$ & medium \\
Admission pathway & $\left(X^{2}(4)=87.726, p<.001\right) ; \mathrm{V}=.279$ & medium \\
Socio-economic residence* & $\left(X^{2}(8)=17.509, p=.025\right) ; \mathrm{V}=.094$ & small \\
Indigenous identification & $\left(X^{2}(4)=2.304, p>.5\right) ; \mathrm{V}=.046$ & ns \\
\hline
\end{tabular}

*Socio-economic backgrounds are defined in university records using Australian Bureau of Statistics post-code classifications. 
Table 2 Comparisons between highest and lowest proportions (\%) in the independent variables across five programs, semester 1, 2012.

\begin{tabular}{|c|c|c|c|c|c|c|}
\hline $\begin{array}{l}\text { Independent } \\
\text { variable }\end{array}$ & $\begin{array}{l}\text { CCJ } \\
\text { (single } \\
\text { degree) } \\
n=549\end{array}$ & $\begin{array}{l}\text { CCJ/ } \\
\text { Law } \\
\mathrm{n}=140\end{array}$ & $\begin{array}{l}\text { CCJ/ } \\
\text { HuServ } \\
\text { n=77 }\end{array}$ & $\begin{array}{l}\text { CCJ/ } \\
\text { PsychSc } \\
\text { n=260 }\end{array}$ & $\begin{array}{l}\text { CCJ/ } \\
\text { ForSc } \\
\text { n=99 }\end{array}$ & $\begin{array}{l}\text { Average } \\
\text { across } \\
\text { programs } \\
\text { n=1125 }\end{array}$ \\
\hline $\begin{array}{l}\text { Study load } \\
<100 \%\end{array}$ & 33.7 & 20.0 & 36.4 & 19.2 & 7.1 & 26.5 \\
\hline $\begin{array}{l}\text { Study load } \\
=100 \%\end{array}$ & 61.9 & 29.3 & 57.1 & $\underline{77.3}$ & $\underline{26.3}$ & 58.0 \\
\hline $\begin{array}{l}\text { Study load } \\
>100 \%\end{array}$ & 4.4 & 50.7 & 6.5 & $\underline{3.5}$ & $\underline{66.7}$ & 15.6 \\
\hline $\begin{array}{l}\text { Gender - } \\
\text { female }\end{array}$ & $\underline{63.4}$ & 77.9 & $\underline{87.0}$ & 78.1 & 85.9 & 72.2 \\
\hline $\begin{array}{l}\text { Age - } \\
\text { younger }\end{array}$ & 77.2 & $\underline{73.6}$ & 75.3 & 83.1 & $\underline{92.9}$ & 79.4 \\
\hline $\begin{array}{l}\text { Language - } \\
\text { English }\end{array}$ & 85.2 & $\underline{84.3}$ & 85.7 & $\underline{95.0}$ & 87.9 & 87.6 \\
\hline Australian born & 77.7 & 80.1 & 80.0 & $\underline{87.6}$ & 78.8 & 80.6 \\
\hline Higher GPA & 43.9 & 62.6 & $\underline{41.1}$ & 55.4 & $\underline{70.0}$ & 51.1 \\
\hline $\begin{array}{l}\text { Higher tertiary } \\
\text { entrance score }\end{array}$ & $\underline{37.6}$ & 85.3 & 50.0 & 66.7 & $\underline{86.5}$ & 54.4 \\
\hline $\begin{array}{l}\text { Preference - } \\
\text { first }\end{array}$ & $\underline{60.0}$ & 65.2 & 68.9 & 77.5 & 88.4 & 68.4 \\
\hline $\begin{array}{l}\text { Pathways - } \\
\text { from school* }\end{array}$ & 74.3 & $\underline{55.0}^{* *}$ & 87.0 & $\underline{91.9}$ & 88.9 & 78.1 \\
\hline $\begin{array}{l}\text { Socioeconomic } \\
\text { level -lower }\end{array}$ & 21.2 & $\underline{18.8}$ & 29.7 & 23.8 & 23.7 & 22.4 \\
\hline $\begin{array}{l}\text { Socioeconomic } \\
\text { level - medium }\end{array}$ & 49.0 & 60.2 & 44.6 & 50.0 & $\underline{62.4}$ & 51.7 \\
\hline Socioeconomic & $\underline{29.8}$ & 21.1 & 25.7 & 26.2 & $\underline{14.0}$ & 26.0 \\
\hline
\end{tabular}


level - higher

Bold - highest \% across programs

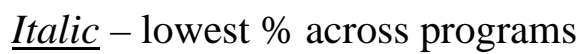

* entry by way of Year 12 secondary school results, or equivalent

** a high proportion of students transfer to the combined CCJ/Law degree from other programs 